\title{
microRNA levels in paraffin-embedded indolent B-cell non-Hodgkin lymphoma tissues from patients chronically infected with hepatitis $B$ or $C$ virus
}

Roberto Bruni ${ }^{1 *}$, Cinzia Marcantonio ${ }^{1}$, Alessandro Pulsoni ${ }^{2}$, Paola Tataseo $^{3}$, Federico De Angelis ${ }^{2}$, Enea Spada ${ }^{1}$, Fabrizio Marcucci ${ }^{4}$, Sara Panfilio ${ }^{2}$, Paolo Bianco ${ }^{5}$, Mara Riminucci ${ }^{5}$, Umbertina Villano $^{1}$, Maria Elena Tosti ${ }^{6}$, Anna Rita Ciccaglione ${ }^{1}$, Alfonso Mele $e^{6,7}$

From Third Workshop of the HCV Study Group in the Calabria Region

Catanzaro, Italy. 04 October 2013

\begin{abstract}
Background: Epidemiological evidence links Hepatitis B Virus (HBV) and Hepatitis C Virus (HCV) to B-cell nonHodgkin lymphoma (B-NHL). These B-NHLs, particularly those associated with HCV, may represent a distinct subgroup with peculiar molecular features, including peculiar expression of microRNAs (miRs).

The aim of the present study was to search for miRs whose level in indolent B-NHL tissues could be associated with HBV or HCV infection.

Methods: Fourteen formalin fixed paraffin embedded (FFPE) tissues from HBV+, HCV+ and HBV-/HCV- indolent BNHL patients were analyzed for levels of 34 selected miRs by quantitative Real-Time PCR. Reactive lymph nodes (RLNs) from HBV-/HCV- patients were included as non-tumor control. Statistical analysis of output data included Pearson and Spearman correlation and Mann-Whitney test and were carried out by the STATA software.

Results: MiR-92a was decreased exclusively in HBV-/HCV- B-NHLs, while miR-30b was increased in HBV+ and HCV+ samples, though only the HCV+ achieved full statistical significance. Analysis of a small subset of B-NHLs belonging to the same histological subtype (Nodal Marginal Zone Lymphoma) highlighted three miRs associated with HCV infection (miR-223, miR-29a and miR-29b) and confirmed decreased level of miR-92a in HBV-/HCV- samples also when considering this restricted B-NHL group.
\end{abstract}

Conclusions: Although caution is needed due to the limited number of analyzed samples, overall the results suggest that differences at the miR expression level exist between indolent B-NHLs developed in patients with or without HBV or HCV infection. The identification of three further miRs associated with HCV by analyzing histologically homogeneous samples suggests that variations of miR levels possibly associated with HBV or HCV may be obscured by the tissue-specific variability of miR level associated with the different histological subtypes of B-NHL. Thus, the identification of further miRs will require, in addition to an increased sample size, the comparison of B-NHL tissues with the same histological classification.

\footnotetext{
* Correspondence: roberto.bruni@iss.it

'Department of Infectious, Parasitic and Immunomediated Diseases, Istituto

Superiore di Sanità, Rome, Italy

Full list of author information is available at the end of the article
} 


\section{Background}

In addition to liver cancer, increasing evidence has linked Hepatitis B Virus (HBV) and Hepatitis C Virus $(\mathrm{HCV})$ to the development of both indolent and aggressive B-cell non-Hodgkin lymphoma (B-NHL). In fact, most epidemiological studies have identified a positive association between B-NHL and HCV and HBV infection [1-4], and a role for both viruses in the pathogenesis of B-NHL has been suggested [5-8].

Further support for HCV playing a role in development of lymphoma has come from reports on the treatment of HCV infection in B-NHL patients [9-12]. In these studies, $\mathrm{HCV}$-associated B-NHLs have been reported to be highly responsive to antiviral therapy: clearance of $\mathrm{HCV}$ resulted in remission of B-NHL, and reappearance of infection was associated with relapse of the disease. Indeed, these observations also suggest that (A) $\mathrm{HCV}$ is involved not only in driving development but also in maintaining B-NHL and (B) HCV-related B-NHLs have specific biological properties, and consequently molecular features, characterizing them as a subset distinct from HCV-unrelated B-NHLs, despite histological similarity [9-12]. However, the mechanism(s) underlying the role of $\mathrm{HCV}$ in the pathogenesis of B-NHLs, as well as the associated molecular alterations, remain(s) to be clarified.

In regards to HBV, a potential link with the pathogenesis of B-NHL in chronic carriers is provided by its ability to infect peripheral blood mononuclear cells, including B lymphocytes [13]. In a recent study, detection of HBV DNA in B-NHL tissues was more frequent than in T-cell NHL or other lymphatic system disease tissues, suggesting that chronic HBV infection in lymph nodes might be associated with B-NHL [14].

MicroRNAs (miRs) are small, non-coding RNAs emerging as key regulators of several cellular processes, including cell growth, development, differentiation and metabolism. Several hundreds of miRs have been characterized and many of them show tissue-specific expression [15]. Although additional mechanisms have been reported, in vertebrates miRs regulate gene expression mainly at the post-transcriptional level, by inhibiting translation of target messenger RNAs by binding to specific, imperfectly complementary, target sites [16-18]. Each miR may regulate hundreds of potential target mRNAs [19].

Evidence for a role of miRs in the pathogenesis of several diseases, including cancer, as well as in the development of innovative tools for molecular diagnosis and prognosis and in the identification of new targets for therapy has been well documented [18-20].

Studies on Formalin Fixed Paraffin Embedded (FFPE) tissues have shown that, in contrast with protein coding mRNAs that are largely degraded, miRs are substantially unaffected by the standard procedures of FFPE tissue preparation [21-23]. The possibility to reliably quantify miRs in slices of FFPE tissues routinely collected for histopathological analysis makes miRs excellent candidates for biomarker discovery using archived FFPE clinical specimens.

Compelling evidence links miRs to HCV biology. MiR122a, highly and specifically expressed in liver but not in B lymphocytes, binds to two closely spaced target sites in the 5 noncoding region of the HCV genome, resulting in upregulation of viral RNA levels [24]. In addition, though not documented in B lymphocytes, the potential for HCV to modulate expression of cellular miRs has been documented in liver cancer cell lines in vitro $[25,26]$.

Several studies have searched for miRs involved in development of B-NHL but, to our knowledge, only one study has investigated the possible influence of $\mathrm{HCV}$ on miR expression in B-NHL, analyzing Splenic Marginal Zone Lymphoma (SMZL), an indolent B-NHL entity with peculiar clinical and molecular features [27]. No study has so far investigated miR expression in other indolent B-NHLs in patients chronically infected by $\mathrm{HBV}$ or $\mathrm{HCV}$.

The aim of the present study was to identify miRs whose level in indolent B-NHLs (nodal marginal zone lymphoma (NMZL), follicular lymphoma (FL), small lymphocitic lymphoma (SLL)) could be related to HBV or HCV infection. B-NHLs from patients positive for $\mathrm{HBV}$ or $\mathrm{HCV}$ are not as frequent as those from negative ones: in Italy approximately 1 out of 20 cases of all BNHLs may be attributable to HCV infection [3], and even less if one considers only the indolent fraction; similar considerations also apply to HBV. Thus, retrieval of indolent B-NHL FFPE samples from HCV or HBV positive patients is not an easy task and only major hematological centers managing large patient numbers and routinely performing virological diagnosis may provide such rather rare samples. In the present study, the archive of the Hematology Center of the "Umberto I" University Hospital of Sapienza University of Rome, diagnosing about 50 indolent B-NHL cases per year and routinely performing virological diagnosis, was searched for samples from patients positive for $\mathrm{HBV}$ or $\mathrm{HCV}$. Available FFPE tissues, including indolent B-NHLs from $5 \mathrm{HBV}$ positive and $4 \mathrm{HCV}$ positive patients and, as controls, 5 indolent B-NHLs and 9 reactive lymph nodes from $\mathrm{HBV} / \mathrm{HCV}$ negative patients, were then analyzed. The level of 34 selected miRs was quantified by RealTime PCR.

\section{Methods \\ Samples}

Fourteen indolent B-NHL samples (lymph node biopsies) had been collected from patients for diagnostic purposes 
before any therapeutic treatment and were classified according to the WHO Classification by expert pathologists. Patient and sample data are reported in Table 1. $\mathrm{HBV}$ or $\mathrm{HCV}$ infection was diagnosed by testing for serological markers of HBV and HCV by commercial kits. FFPE samples for histopathological analysis were obtained by standard procedures.

The study was approved by the Ethical Committee of the participating Centers. Informed consent was obtained from the patients. The study is in accordance with the ethical standards of the institutional committees and with the Helsinki Declaration.

Nine lymph nodes with minor reactive changes (Reactive Lymph Nodes, RLNs) were also included in the study as non-neoplastic controls. RLNs were analyzed exclusively for the level of the $5 \mathrm{miRs}$ (miR-92a, miR30b, miR-223, miR-29a and miR-29b) that showed association with presence/absence of HBV or HCV infection in B-NHL patients.

\section{Total RNA extraction from FFPE tissue sections and quantification}

Total RNA was extracted from FFPE tissue samples by the miRNeasy FFPE kit (QIAGEN), according to the manufacturer's instructions. Further details are reported in additional file 1. RNA concentration was determined by the Agilent RNA 6000 Nano Kit on an Agilent 2100 Bioanalyzer (Agilent Technologies), and was calculated as the mean value from two independent runs. Accurate RNA concentration estimate was included to avoid normalization of Real-Time PCR data: normalization was shown to be unnecessary if accurate estimation of RNA concentration is carried out [28].

\section{Table 1 Patient and sample data.}

\begin{tabular}{ccccc}
\hline $\begin{array}{c}\text { Sample } \\
\text { ID }\end{array}$ & $\begin{array}{c}\text { HBV or HCV } \\
\text { infection }\end{array}$ & $\begin{array}{c}\text { Subtype of } \\
\text { B-NHL }\end{array}$ & $\begin{array}{c}\text { Patient } \\
\text { Age }\end{array}$ & $\begin{array}{c}\text { Patient } \\
\text { Gender }\end{array}$ \\
\hline 1 & HBV & SLL & 66 & $\mathrm{~F}$ \\
2 & HBV & $\mathrm{FL}$ & 49 & $\mathrm{M}$ \\
3 & HBV & SLL & 65 & $\mathrm{M}$ \\
4 & HBV & NMZL & 73 & $\mathrm{~F}$ \\
6 & HBV & $\mathrm{FL}$ & 55 & $\mathrm{~F}$ \\
8 & HCV & NMZL & 74 & $\mathrm{M}$ \\
9 & HCV & NMZL & 73 & $\mathrm{~F}$ \\
10 & HCV & NMZL & 66 & $\mathrm{~F}$ \\
12 & HCV & $\mathrm{FL}$ & 60 & $\mathrm{M}$ \\
14 & Negative & $\mathrm{FL}$ & 72 & $\mathrm{M}$ \\
15 & Negative & $\mathrm{SLL}$ & 52 & $\mathrm{~F}$ \\
16 & Negative & NMZL & 62 & $\mathrm{M}$ \\
17 & Negative & NMZL & 69 & $\mathrm{~F}$ \\
18 & Negative & NMZL & 76 & $\mathrm{M}$ \\
\hline
\end{tabular}

HBV: Hepatitis B Virus; HCV: Hepatitis C Virus; B-NHL: B-cell Non Hodgkin Lymphoma; NMZL: Nodal Marginal Zone Lymphoma; FL: Follicular Lymphoma; SLL: Small Lymphocytic Lymphoma; M: Male; F: Female.
miR quantification by Real-Time PCR

The list of assayed miRs is reported in Table 2. A set of 34 miRs was selected for quantification including (A) the 33 most abundantly expressed miRs from the so called "B-cell miRNome", reporting miR expression from three normal B-cell types (naïve, memory and germinal center centroblasts) and from a Burkitt lymphoma cell line [29] and (B) miR-26b, which was included despite the very low level in B-cell miRNome, because of its recently reported association with HCV in SMZL [27]. Further details are reported in additional file 1.

miR level was analyzed by Real-Time PCR in 96-well plates with TaqMan commercial assays (Applied Biosystems). In order to exclude artifacts due to inter-run variations, all B-NHL samples were assayed for each miR in the same Real-Time PCR run. Triplicate reactions were carried out for each miR/sample. Output raw $\mathrm{Ct}$ data from RealTime PCR were processed by EXCEL functions, including simple statistical analysis. Processed data were analyzed for statistical significance by the STATA software.

\section{Results}

\section{Reliability of data from FFPE B-NHL tissues}

Total RNA extracted from 14 FFPE B-NHLs was analyzed for 34 selected miRs by commercial Real-Time PCR assays. Patient and sample data are reported in Table 1, and the list of assayed miRs in Table 2.

As a first step, the reliability of the obtained Real-Time PCR data was evaluated. The expression of several miRs is so exquisitely tissue specific that it is being used to trace the tissue of origin of metastases from unknown primary tumors [30-32]. We took advantage of a previous study reporting the miR levels from 40 normal human tissues, including lymph node, in which miRs were quantified by the same Real-Time PCR method used in the present study; the raw $\mathrm{Ct}$ values were available as supplementary information [33]. In that study, total RNA samples from

Table 2 List of the assayed 34 miRs.

\begin{tabular}{|c|c|c|c|c|}
\hline hsa-let-7a & hsa-miR-138 & hsa-miR-16 & hsa-miR-21 & hsa-miR-29b \\
\hline hsa-let-7b & $\begin{array}{l}\text { hsa-miR-140- } \\
3 p\end{array}$ & $\begin{array}{l}\text { hsa-miR-17- } \\
5 p\end{array}$ & hsa-miR-221 & hsa-miR-29c \\
\hline hsa-let-7f & $\begin{array}{l}\text { hsa-miR-142- } \\
3 p\end{array}$ & hsa-miR-191 & hsa-miR-223 & hsa-miR-30b \\
\hline hsa-let-7g & $\begin{array}{l}\text { hsa-miR-142- } \\
5 p\end{array}$ & $\begin{array}{l}\text { hsa-miR- } \\
\text { 193b }\end{array}$ & hsa-miR-25 & hsa-miR-30c \\
\hline hsa-let-7i & hsa-miR-150 & hsa-miR-19a & hsa-miR-26a & $\begin{array}{l}\text { hsa-miR-339- } \\
5 p\end{array}$ \\
\hline $\begin{array}{l}\text { hsa-miR- } \\
106 b\end{array}$ & hsa-miR-15a & hsa-miR-19b & ${ }_{*}^{\text {hsa-miR-26b }}$ & hsa-miR-92a \\
\hline $\begin{array}{l}\text { hsa-miR- } \\
125 b\end{array}$ & hsa-miR-15b & hsa-miR-20a & hsa-miR-29a & \\
\hline
\end{tabular}

* not selected from B-cell miRNome; it was included because found to be down-regulated in SMZLs from HCV positive patients [27]. 
commercial sources, extracted from frozen tissues, were used.

The average Pearson correlation between the levels of the 34 miRs in our set of 14 B-NHLs and their levels in 40 human tissues is shown in additional file 2. B-NHLs exhibited high correlation with lymph node (mean $\mathrm{r}=$ $0.76 \pm 0.09$ ), low/moderate correlation with thymus and spleen (mean $r=0.44 \pm 0.11$ and $0.42 \pm 0.09$, respectively) and little if any correlation with the remaining tissues (mean $r<0.3 \pm 0.10$ ). This result suggests good reliability of our data from FFPE B-NHL tissues, as they show the expected correlation with data from frozen immune and other tissues reported in a previous independent study.

In addition, a recent study reported a miR signature allowing to distinguish NMZLs from FLs: the levels of miR-221, miR-223 and let-7f, as determined by Real-Time PCR assays, were increased in NMZLs compared with FLs [34]. The median expression of these three miRs was compared in our NMZL cases $(n=7)$ vs. FL cases $(n=4)$. Increased miR-221 and miR-223 levels were observed in NMZLs (4.9 and 4.4 fold, respectively), while similar levels of let-7f were present in both subtypes (1.1 fold in NMZLs vs. FLs); however, analysis of let-7f values from individual samples showed an outlier in one of the four FL cases (sample ID: 6): by excluding this sample, 3.2 fold higher level was present in NMZLs vs. the remaining FLs (data not shown). It can be concluded that the previously described signature of NMZLs vs. FLs is essentially observed also in the present study.

\section{miRs differentially expressed in B-NHLs from HBV or HCV infected vs. uninfected patients}

The level of the 34 miRs was then analyzed to search for a possible differential expression in association with presence or absence of HBV or HCV infection. B-NHLs from HBV positive patients (HBV+ B-NHLs) $(n=5)$ and from $\mathrm{HCV}$ positive patients $(\mathrm{HCV}+\mathrm{B}-\mathrm{NHLs})(\mathrm{n}=4)$ were compared with the control B-NHL group from patients negative for HBV or HCV infection (Ctrl B-NHL) $(n=5)$.

Most miRs, including miR-26b previously reported to be associated with HCV in SMZLs [27], did not show significant differences, except two of them, miR-92a and miR-30b, with p-values achieving or approaching statistical significance (Figure 1A-B; fold vs. control B-NHLs and $p$ values are summarized in Figure $1 C$ ). The median levels of miR-92a and miR-30b in HBV+ and $\mathrm{HCV}+$ B-NHLs were higher than in control B-NHLs (miR-92a: 6.0 fold and 7.5 fold, respectively; miR-30b: 1.7 fold and 1.8 fold, respectively).

The level of miR-92a and miR-30b was then analyzed in reactive lymph nodes (RLNs) and compared with the levels in the B-NHL groups (Figure $1 \mathrm{~A}-\mathrm{B}$; folds and $p$ values are summarized in Figure 1D). The median level of miR-92a in both HBV+ and HCV+ B-NHLs did not differ from that observed in RLNs ( $\mathrm{p}=\mathrm{n}$.s.), while in Ctrl BNHLs it was 6.6 fold lower $(\mathrm{p}=0.014)$ (Figure $1 \mathrm{~A}, \mathrm{D})$. In contrast, the median level of miR-30b in $\mathrm{HBV}+$ and $\mathrm{HCV}$ + B-NHLs, though not reaching statistical significance, was 1.4 and 1.5-fold higher than in RLNs, respectively, while in Ctrl B-NHLs it was similar to that observed in RLNs (Figure $1 \mathrm{~B}, \mathrm{D}$ ).

\section{Correlated expression of miR-30b and miR-92a in B-NHLs}

The observed pattern of miR-92a and miR-30b in BNHLs and RLNs suggested that the levels of these miRs could be correlated and, thus, this possibility was formally evaluated by Spearman ( $\rho$ ) statistical test.

miR-30b and miR-92a levels were found to be correlated in B-NHLs ( $\rho=0.73 ; p=0.003)$, but not in RLNs ( $\rho=-0.42 ; p=0.26)$. In B-NHL subgroups, statistically significant and very high correlation of miR-30b and miR-92a levels was found in Ctrl B-NHLs ( $\rho=0.90$; $=$ 0.037), moderate/high correlation, but not statistically significant, in the HBV+B-NHLs $(\rho=0.70 ; p=0.19)$ and no significant correlation in the $\mathrm{HCV}+\mathrm{B}-\mathrm{NHLs}$ $(\rho=-0.20 ; p=0.80)$, apparently suggesting that correlation is absent in HCV+ B-NHLs. However, examination of miR-92a and miR-30b levels in individual samples showed that in the $\mathrm{HCV}+$ group the absence of correlation was due to the individual FL sample, while the remaining three NMZLs showed a clearly correlated expression trend (data not shown), suggesting that heterogeneity between subtypes may result in decreased correlation.

To evaluate if histological subtype could be a factor contributing to the correlated expression of miR-92a and miR-30b, correlation was also analyzed in B-NHLs grouped by histological subtype. In SLL, correlation and statistical significance could not be formally evaluated because only three samples were available, not allowing a reliable Spearman test, but examination of miR-92a and miR-30b levels in individual SLL samples showed a correlated expression trend (data not shown). In FL, miR-30b and miR-92a levels were highly correlated, though not reaching statistical significance $(\rho=0.80 ; p$ $=0.20$ ), while in NMZL they were very highly correlated and statistically significant $(\rho=0.96 ; p=0.0005)$.

\section{Search for miRs associated with HCV infection in NMZLs}

As suggested by the above analysis, and also from a theoretical point of view, a comparison of histologically homogeneous samples might be more suitable to detect virus-associated hallmarks, because this approach would exclude the variability related to histological differences.

Due to the small number of available samples, this analysis could be carried out only for NMZLs, and in 

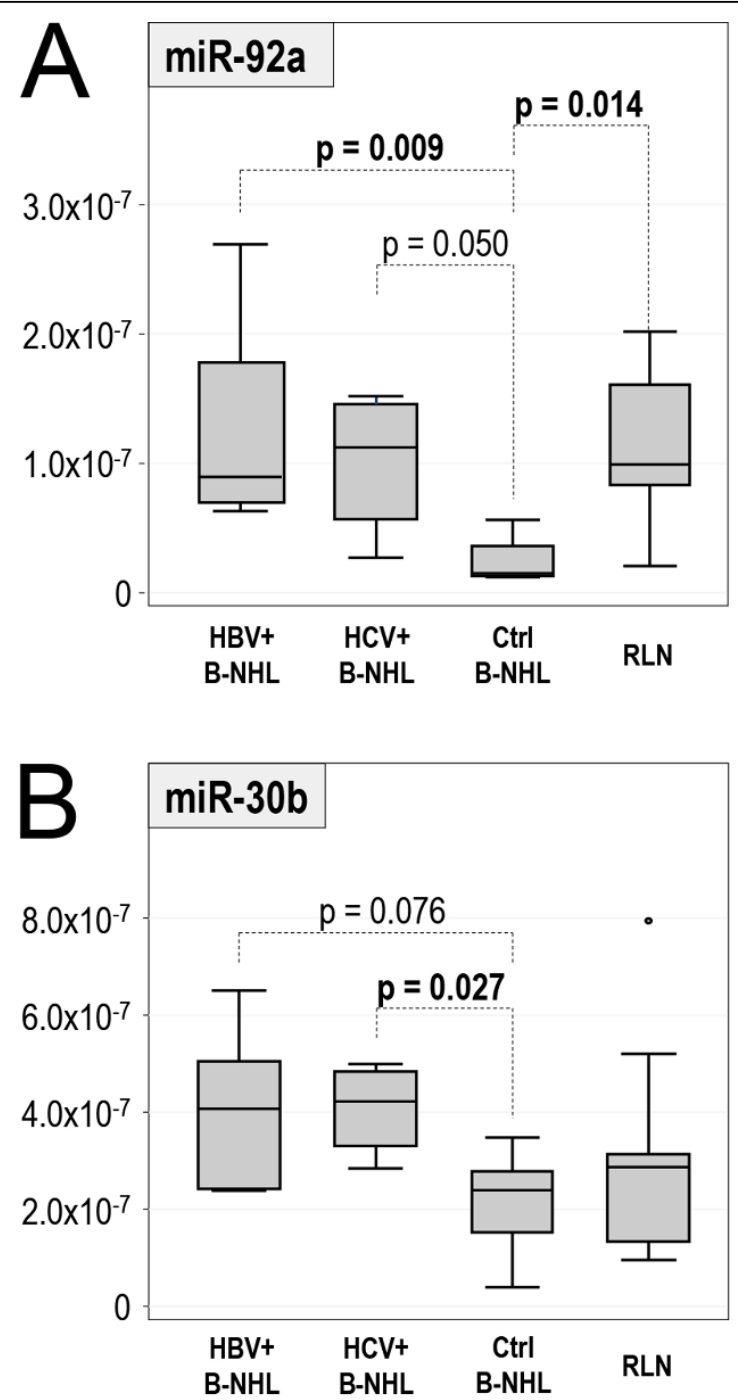

\begin{tabular}{|l|c|c|c|c|}
\cline { 2 - 6 } \multicolumn{2}{c|}{} & \multicolumn{2}{c|}{ miR-92a } & \multicolumn{2}{c|}{ miR-30b } \\
\hline $\begin{array}{c}\text { Comparison } \\
\text { vs. Ctrl B-NHLs }\end{array}$ & Fold & $p$ & Fold & $p$ \\
\hline $\mathrm{HBV}+\mathrm{B}-\mathrm{NHL}$ & +6.0 & $\mathbf{0 . 0 0 9}$ & +1.7 & 0.08 \\
\hline $\mathrm{HCV}+\mathrm{B}-\mathrm{NHL}$ & +7.5 & 0.050 & +1.8 & $\mathbf{0 . 0 3}$ \\
\hline
\end{tabular}

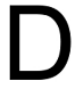

\begin{tabular}{|l|c|c|c|c|}
\hline $\begin{array}{c}\text { Comparison } \\
\text { vs. RLNs }\end{array}$ & Fold & $p$ & Fold & $p$ \\
\hline $\mathrm{HBV}+\mathrm{B}-\mathrm{NHL}$ & -1.1 & 0.74 & +1.4 & 0.32 \\
\hline $\mathrm{HCV}+\mathrm{B}-\mathrm{NHL}$ & +1.1 & 0.64 & +1.5 & 0.28 \\
\hline Ctrl B-NHL & -6.6 & $\mathbf{0 . 0 1 4}$ & -1.2 & 0.55 \\
\hline
\end{tabular}

Figure 1 Level of miR-92a and miR-30b in HBV+ B-NHL, HCV+ B-NHL, Ctrl B-NHL and RLN groups. Box-plot representation of the level of miR-92a (A) and miR-30b (B) in HBV+ B-NHL, HCV+ B-NHL, Ctrl B-NHL and RLN sample groups. HBV+ B-NHL: B-NHLs from HBV positive patients; HCV+ B-NHL: B-NHLs from HCV positive patients; Ctrl B-NHL: control B-NHLs from patients negative for both HBV and HCV. The level is reported as $2^{-\mathrm{Ct}}$ values. $\mathrm{p}$ values $<0.1$ are reported, and those $<0.05$ are shown in bold. $\mathbf{C}$ and $\mathbf{D}$ : summary of fold-change (vs. reference $\mathrm{Ctrl}$ B-NHL and RLN, respectively) and p-value (Mann-Withney test). Fold-change was calculated as ratio between median level of each group vs. median level of the reference group. 
relation with $\mathrm{HCV}$ but not HBV: three NMZLs from $\mathrm{HCV}$-positive patients (HCV+ NMZLs) were compared with three control NMZLs from HCV-negative patients (Ctrl NMZLs).

Four out of the 34 assayed miRs showed a statistically significant different level between the groups (Figure 2): in HCV+ NMZLs, median levels of both miR-223 and miR-92a were 3.8-fold higher than in Ctrl NMZLs ( $\mathrm{p}=$ 0.049 for both miRs), while miR-29a and miR-29b were
1.6- and 1.2-fold lower, respectively, than in Ctrl NMZLs ( $\mathrm{p}=0.049$ for both) (Figure $2 \mathrm{~A}-\mathrm{B}$ ).

Then, the levels of miR-223, miR-92a, miR-29a and miR-29b were determined in nine RLN controls and compared with those in HCV+ and Ctrl NMZLs.

miR-223 level in HCV+ NMZLs was 6.7-fold higher than in RLNs ( $p=0.013$ ), while in Ctrl NMZLs it did not show a significant difference $(\mathrm{p}=0.78)$ (Figure $2 \mathrm{~A}, \mathrm{C})$ : thus, miR223 was up-regulated in HCV+ but not in Ctrl NMZLs.

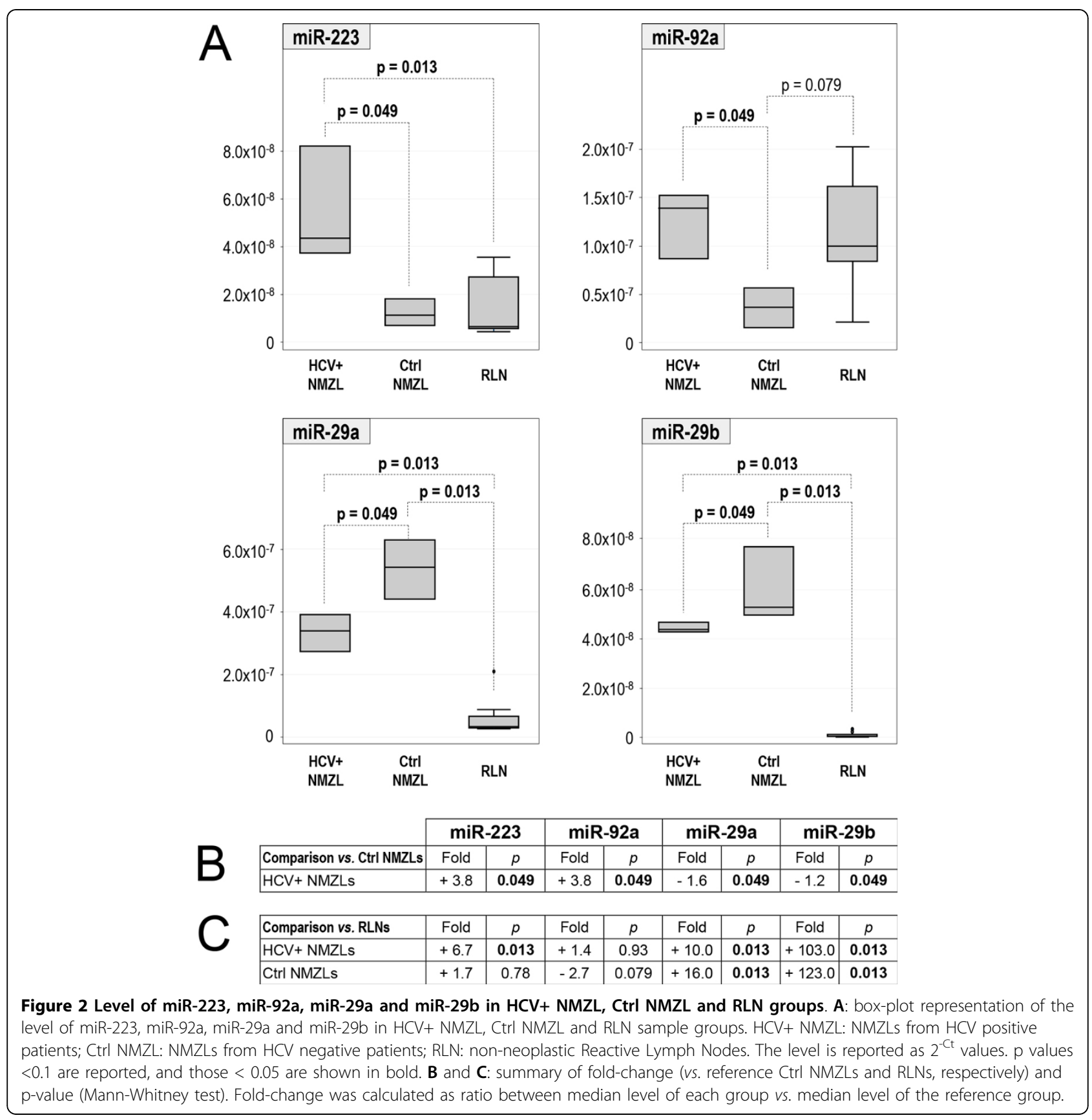


miR-92a level in HCV+ NMZLs showed no significant difference versus RLNs ( $\mathrm{p}=0.93$ ) while in Ctrl NMZLs it showed a 2.7-fold lower level than in RLNs (tending to significance, $\mathrm{p}=0.079$ ) (Figure 2), a result similar to that obtained by the above analysis of all available samples, in which B-NHLs negative for HBV and HCV (that included the three NMZLs of the present comparison) showed lower miR-92a levels than RLNs (see previous paragraphs and Figure 1).

Finally, miR-29a and miR-29b levels in both HCV+ and Ctrl NMZLs were significantly higher than in RLNs ( $p=0.013$ in both comparisons): however, the degree of up-regulation in the $\mathrm{HCV}+$ group was significantly lower than in the HCV-Ctrl group (miR-29a: 10-fold $v s$. 16-fold respectively, $\mathrm{p}=0.0495$; miR-29b: 103-fold $v s$. 123-fold respectively, $\mathrm{p}=0.0495$ ) (Figure $2 \mathrm{~A}, \mathrm{C}$ ).

Then, the comparison versus RLNs of miRs up-regulated in HCV+ NMZLs (miR-223, miR-92a, miR-29a and miR-29b) was extended to the whole group of fourteen B-NHLs. In contrast to miR-223 and miR-92a, showing no significant differences, the increased miR-29a and miR-29b level observed in both HCV+ and Ctrl NMZLs was common to all other B-NHLs too: median level in B-NHLs was significantly higher than in RLNs (miR-29a: 11 -fold, $\mathrm{p}=0.002$; miR-29b: 106-fold, $\mathrm{p}=0.0002$ ) (data not shown).

In addition, correlation analysis by the Spearman test showed that the miR-29a and miR-29b levels were highly correlated in B-NHLs $(\rho=0.916, \mathrm{p}<0.0001)$, but not in RLNs $(\rho=-0.583, p=0.099)$. In B-NHL histological subgroups, high correlation values were found in the HBV+ and Ctrl B-NHL subgroups ( $\rho=0.80$ in both groups, albeit not reaching statistical significance: $p=0.10$ in both) but not in the HCV+ subgroup $(\rho=0.20, p=0.80)$. The lack of statistical significance in individual B-NHL subgroups, but not in the whole group of B-NHLs, is likely an effect of the small sample size of the individual subgroups.

\section{Discussion}

FFPE tissues have been reported in previous studies to be as suitable as frozen tissues for quantification of miR expression: this finding was confirmed in the present study. The results of the correlation analysis of Real-Time PCR data from our set of FFPE B-NHLs and data previously reported from 40 different frozen tissues showed the expected correlations: miR profiles from B-NHLs were highly correlated with profiles from lymph node tissue, to a lesser extent with spleen and thymus and not at all with the remaining 37 tissues. In addition, a previously described miR signature distinguishing NMZLs from FLs was observed also in samples of the present study.

Association of miR-26b with HCV in SMZLs was reported in a previous study [27]. No significant association of miR-26b with HCV was observed in our set of B-NHLs, that included NMZLs, FLs, SLLs, but not SMZLs. In another lymphoma subtype, Diffuse Large B Cell Lymphoma (DLBCL), it has been reported that its location is an important factor in determining the differential expression of miRNAs: in fact, two miRs (miR-17-5p and miR-127) showed significant level differences depending on the site of presentation (central nervous system, testicular, nodal) [35]. Thus, it is possible that HCV may affect miR-26b in SMZL due to the splenic localization of that B-NHL.

Compared with Ctrl B-NHLs, the level of miR-92a and miR-30b appeared to be increased in HBV+ and HCV+ B-NHLs. However, compared with non-neoplastic RLNs the miR-92a levels appeared unchanged in the HBV+ and $\mathrm{HCV}+$ groups and decreased in B-NHLs negative for $\mathrm{HBV}$ and $\mathrm{HCV}$, suggesting down-regulation in Ctrl $\mathrm{B}-\mathrm{NHLs}$, rather than up-regulation in $\mathrm{HBV}+$ and $\mathrm{HCV}+$ B-NHLs (Figure 1A). In contrast, the level of miR-30b in $\mathrm{HBV}+$ and $\mathrm{HCV}+\mathrm{B}-\mathrm{NHLs}$ was increased also with respect to RLNs; thus, miR-30b up-regulation appears to be associated with HBV and HCV, though the relevance of this result is limited by the lack of significance in the comparison with RLNs, a result influenced by the small level of variation and by the limited number of available samples.

Although miR-92a is usually up-regulated in tumors compared to normal tissues [36,37], our finding is not surprising because miR-92a down-regulation in tumors has also been described, e.g. in breast cancer in association with aggressive features and increased tumor macrophage infiltration [38]. This underscores the importance of carefully studying miR expression in specific tumor types, because a miR can show different expression levels in different tumor types.

The unchanged level of miR-92a in HBV+ and HCV+ B-NHLs, as opposed to the decrease in HBV-/HCV- BNHLs, suggests either that HBV and HCV infection might play an opposite, compensatory role on miR-92a level or that in these patients B-NHL develops in the absence of miR-92a down-regulation.

Levels of miR-92a and miR30b were found to be highly correlated in B-NHLs but not in RLNs, suggesting that the correlation between these miRs is a tumor-associated alteration. This finding implies that the observed levels of miR-92a in HBV+ B-NHLs, HCV+ B-NHLs and RLNs, though similar, actually result from different underlying mechanisms. The correlation of miR-92a and miR-30b was found to be very high and significant in Ctrl B-NHLs, but was less pronounced in $\mathrm{HBV}+$ and $\mathrm{HCV}+$ B-NHLs, suggesting these viral infections may play some role in modifying the correlated expression of these miRs.

Overall, even considering the limited number of available samples, the results appear to suggest that some differences at the miR level indeed exist between indolent B-NHLs from patients with or without HBV or HCV 
infection. However, they were difficult to detect, mainly because of the small sample size, that negatively affected the statistical significance, but likely also because of the association of miR expression with tissue specificity and differentiation [39]. Indeed, the different miR levels associated with different histological subtypes likely represent a bias able to obscure small changes associated with HBV or HCV infection, preventing the identification of those miRs actually influenced by these viral infections, but whose variation is smaller than that observed among different histological subtypes.

Consistent with this view, analysis of B-NHL tissues belonging to the same histological subtype (NMZL) led to identification of four miRs (miR-92a, miR-223, miR$29 \mathrm{a}$ and miR-29b) that showed significantly different levels between $\mathrm{HCV}+$ and $\mathrm{HCV}$ - cases, despite the small sample size. Actually, the comparison with RLNs suggested down-regulation of miR-92a in Ctrl NMZLs, rather than up-regulation in HCV+ NMZLs, confirming also in the restricted NMZL subgroup what observed analyzing all B-NHL cases (see above).

In contrast to miR-92a, miR-223 was up-regulated in HCV + NMZLs: the level was 3.8-folds higher than in Ctrl NMZLs and 6.7-folds higher than in RLNs, suggesting a role for HCV in increasing the miR-223 level.

MiR-29a and miR-29b were up-regulated in both HCV+ and Ctrl NMZLs compared to RLNs, and extension of the analysis to all available B-NHLs showed that up-regulation of these miRs was common to the whole B-NHL group, a feature also shared with another lymphoid malignancy, chronic lymphocytic leukemia [40]. However, up-regulation in the HCV+ NMZLs was significantly lower than in the Ctrl NMZLs, suggesting a role for HCV in "dampening" the up-regulation. This hypothesis is supported by the observation that miR-29 was down-regulated by $\mathrm{HCV}$ infection in hepatocytes [41], and a similar effect might also occur in HCV-infected cells other than hepatocytes, such as B-cells.

Intriguingly, both miR-223 and miR-29a, associated with $\mathrm{HCV}$ in the present study, have been reported to be activated by a common transcription factor, CEBPA [42-45]. The possible interaction of HCV with this factor, if any, is expected to be complex, because CEBPA leads to increased levels of both miR-223 and miR-29a, while HCV was associated with increased miR-223 but decreased miR-29a.

\section{Conclusions}

Although the significance is hampered by the limited number of available samples, the present study suggests the existence of differences at the miR expression level between indolent B-NHLs developed in patients with or without $\mathrm{HBV}$ or $\mathrm{HCV}$ infection.
Analysis of histologically heterogeneous B-NHLs showed that miR-30b was increased in $\mathrm{HBV}+$ and $\mathrm{HCV}$ + cases, while miR-92a was decreased in cases negative for these infections; the levels of these miRs proved to be correlated in B-NHLs but not in RLNs.

Analysis of a small subset of B-NHLs with the same histological subtype classification (NMZL) showed association of four miRs (miR-92a, miR223, miR-29a and miR29b) with HCV infection. Though caution is needed due to the limited number of analyzed samples, nevertheless this result suggests that heterogeneity of histological subtypes may represent an obstacle for the identification of miRs possibly influenced by HBV or HCV. Thus, further studies aiming at identifying miRs associated with HBV and HCV in B-NHLs will require both a larger sample size and the comparison of B-NHL tissues with the same histological subtype classification.

\section{Additional material}

\section{Additional file 1: Additional details of methods \\ Additional file 2: Correlation of miR profiles from B-NHLs with miR} profiles from 40 different tissues

\section{List of abbreviations}

HBV: Hepatitis B Virus; HCV: Hepatitis C Virus; HBV+: HBV positive; HCV+: HCV positive; NHL: Non-Hodgkin Lymphoma; B-NHL: B-cell Non-Hodgkin Lymphoma; NMZL: Nodal Marginal Zone Lymphoma; SMZL: Splenic Marginal Zone Lymphoma; FL: Follicular Lymphoma; SLL: Small Lymphocytic Lymphoma; miR: microRNA; FFPE: Formalin Fixed Paraffin Embedded.

\section{Competing interests}

The authors declare that they have no competing interests.

\section{Authors' contributions}

RB contributed to design research, carried out tissue RNA extraction and quantification, analyzed data, and wrote the manuscript; CM, PT and UV performed miR quantification experiments; AP and FDA collected clinical data and contributed to design research; SP contributed to collect clinical data; MR and PB carried out histopathological analysis and subtype classification of tissue specimens; MET performed statistical analysis; ARC contributed to design research and analyze the data; ES, FM and AM contributed to design research.

\section{Acknowledgements}

The authors are grateful to Bernardo Moretti for competent and careful preparation of FFPE tissues and microtome tissue sections.

\section{Declarations}

The publication of this supplement was partly supported by an unrestricted grant provided by Roche. The articles were independently prepared by the authors with no input from Roche. Roche was not involved in selecting the articles for the supplement.

This article has been published as part of BMC Infectious Diseases Volume 14 Supplement 5, 2014: Proceedings of the Third Workshop of the HCV Study Group in the Calabria Region: Results from the South Italian Network for Rational Guidelines and International Epidemiology (SINERGIE) Project. The full contents of the supplement are available online at http://www. biomedcentral.com/bmcinfectdis/supplements/14/S5. 


\section{Authors' details}

'Department of Infectious, Parasitic and Immunomediated Diseases, Istituto Superiore di Sanità, Rome, Italy. ${ }^{2}$ Department of Cellular Biotechnologies and Hematology, Sapienza University, Rome, Italy. ${ }^{3}$ ASL Avezzano-Sulmona, Transfusional Medicine and Molecular Biology Laboratory, Sulmona, Italy. ${ }^{4}$ Scientific Directorate, Regina Elena Cancer Institute, Rome, Italy. ${ }^{5}$ Department of Molecular Medicine, Sapienza University, Rome, Italy. ${ }^{6}$ National Centre for Epidemiology, Surveillance and Health Promotion, Istituto Superiore di Sanità, Rome, Italy. ${ }^{7}$ Associazione Calabrese di Epatologia (ACE), Pellaro (RC), Italy.

Published: 5 September 2014

\section{References}

1. Kuniyoshi M, Nakamuta M, Sakai H, Enjoji M, Kinukawa N, Kotoh K Fukutomi M, Yokota M, Nishi H, Iwamoto H, Uike N, Nishimura J, Inaba S, Maeda Y, Nawata H, Muta K: Prevalence of hepatitis B or C virus infections in patients with non-Hodgkin's lymphoma. J Gastroenterol Hepatol 2001, 16:215-219.

2. Iwata H, Matsuo K, Takeuchi K, Kishi Y, Murashige N, Kami M: High incidences of malignant lymphoma in patients infected with hepatitis B or hepatitis C virus. Haematologica 2004, 89(3):369-370.

3. Mele A, Pulsoni A, Bianco E, Musto P, Szklo A, Sanpaolo MG, lannitto E, De Renzo A, Martino B, Liso V, Andrizzi C, Pusterla S, Dore F, Maresca M, Rapicetta M, Marcucci F, Mandelli F, Franceschi S: Hepatitis C virus and Bcell non-Hodgkin lymphomas: an Italian multicenter case-control study. Blood 2003, 102(3):996-999.

4. Marcucci F, Mele A, Spada E, Candido A, Bianco E, Pulsoni A, Chionne P, Madonna E, Cotichini R, Barbui A, De Renzo A, Dore F, lannitto E, Liso V, Martino B, Montanaro M, Pagano L, Musto P, Rapicetta M: High prevalence of hepatitis B virus infection in B-cell non-Hodgkin's lymphoma. Haematologica 2006, 91:554-557.

5. Hjalgrim H, Engels EA: Infectious aetiology of Hodgkin and non-Hodgkin lymphomas: a review of the epidemiological evidence. J Intern Med 2008, 264(6):537-548.

6. Nath A., Agarwal R., Malhotra P., Varma S: Prevalence of Hepatitis B virus infection in Non-Hodgkin's lymphoma: a systematic review and metaanalysis. Intern Med J 2010, 40(9):633-641.

7. Marcucci F, Mele A: Hepatitis viruses and non-Hodgkin lymphoma: epidemiology, mechanisms of tumorigenesis, and therapeutic opportunities. Blood 2011, 117(6):1792-1798.

8. Marcucci F, Spada E, Mele A, Caserta CA, Pulsoni A: The association of hepatitis $B$ virus infection with B-cell non-Hodgkin lymphoma - a review. Am J Blood Res 2012, 2(1):18-28.

9. Hermine O, Lefrere F, Bronowicki JP, Mariette X, Jondeau K, EclacheSaudreau V, Delmas B, Valensi F, Cacoub P, Brechot C, Varet B, Troussard $X$ : Regression of splenic lymphoma with villous lymphocytes after treatment of hepatitis C virus infection. N Engl J Med 2002, 347:89-94.

10. Kelaidi C, Rollot F, Park S, Tulliez M, Christoforov B, Calmus Y, Podevin P, Bouscary D, Sogni P, Blanche P, Dreyfus F: Response to antiviral treatment in hepatitis C virus-associated marginal zone lymphomas. Leukemia 2004, 18:1711-1716.

11. Vallisa D, Bernuzzi P, Arcaini L, Sacchi S, Callea V, Marasca R, Lazzaro A, Trabacchi E, Anselmi E, Arcari AL, Moroni C, Bertè R, Lazzarino M, Cavanna L: Role of anti-hepatitis C virus (HCV) treatment in HCV-related, low grade, B-cell non-Hodgkin's lymphoma: a multicenter Italian experience. J Clin Oncol 2005, 23:468-473.

12. Levine AM, Shimodaira S, Lai MM: Treatment of HCV-related mantle-cell lymphoma with ribavirin and pegylated interferon alfa. $N$ Engl J Med 2003, 349:2078-2079.

13. Pontisso P, Vidalino L, Quarta S, Gatta A: Biological and clinical implications of HBV infection in peripheral blood mononuclear cells. Autoimmun Rev 2008, 8(1):13-17.

14. Wang F, Yuan S, Teng KY, Garcia-Prieto C, Luo HY, Zeng MS, Rao HL, Xia Y, Jiang $W Q$, Huang $H Q$, Xia ZJ, Sun XF, Xu RH: High hepatitis B virus infection in B-cell lymphoma tissue and its potential clinical relevance. Eur J Cancer Prev 2012, 21(3):261-267.

15. Bartel DP: MicroRNAs: genomics, biogenesis, mechanism, and function. Cell 2004, 116(2):281-297.
16. Filipowicz W, Bhattacharyya SN, Sonenberg N: Mechanisms of posttranscriptional regulation by microRNAs: are the answers in sight? Nat Rev Genet 2008, 9:102-114.

17. Wu L, Belasco JG: Let me count the ways: mechanisms of gene regulation by miRNAs and siRNAs. Mol Cell 2008, 29:1-7.

18. Iorio MV, Croce CM: MicroRNA dysregulation in cancer: diagnostics, monitoring and therapeutics. A comprehensive review. EMBO Mol Med 2012, 4(3):143-159.

19. Bartel DP: MicroRNAs: target recognition and regulatory functions. Cell 2009, 136:215-233.

20. Cho WC: MicroRNAs: potential biomarkers for cancer diagnosis, prognosis and targets for therapy. Int J Biochem Cell Biol 2010, 42(8):1273-1281.

21. Doleshal M, Magotra AA, Choudhury B, Cannon BD, Labourier E, Szafranska AE: Evaluation and Validation of Total RNA Extraction Methods for MicroRNA Expression Analyses in Formalin-Fixed, Paraffin-Embedded Tissues. J Mol Diagn 2008, 10(3):203-211.

22. Szafranska AE, Davison TS, Shingara J, Doleshal M, Riggenbach JA, Morrison $C D$, Jewell $S$, Labourier E: Accurate molecular characterization of formalin-fixed, paraffin-embedded tissues by microRNA expression profiling. J Mol Diagn 2008, 10(5):415-423.

23. Xi Y, Nakajima G, Gavin E, Morris CG, Kudo K, Hayashi K, Ju J: Systematic analysis of microRNA expression of RNA extracted from fresh frozen and formalin-fixed paraffin-embedded samples. RNA 2007, 13(10):1668-1674.

24. Jopling CL, Yi MK, Lancaster AM, Lemon SM, Sarnow P: Modulation of hepatitis $C$ virus RNA abundance by a liver-specific microRNA. Science 2005, 309(5740):1577-1581

25. Braconi C, Valeri N, Gasparini P, Huang N, Taccioli C, Nuovo G, Suzuki T, Croce CM, Patel T: Hepatitis C Virus Proteins Modulate MicroRNA Expression and Chemosensitivity in Malignant Hepatocytes. Clin Cancer Res 2010, 16:957-966

26. Bruni R, Marcantonio C, Tritarelli E, Tataseo P, Stellacci E, Costantino A, Villano U, Battistini A, Ciccaglione AR: An integrated approach identifies IFN-regulated microRNAs and targeted mRNAs modulated by different HCV replicon clones. BMC Genomics 2011, 12:485.

27. Peveling-Oberhag J, Crisman G, Schmidt A, Döring C, Lucioni M, Arcaini L, Rattotti S, Hartmann S, Piiper A, Hofmann WP, Paulli M, Küppers R, Zeuzem S, Hansmann ML: Dysregulation of global microRNA expression in splenic marginal zone lymphoma and influence of chronic hepatitis $C$ virus infection. Leukemia 2012, 26(7):1654-1662.

28. Huggett J, Dheda K, Bustin S, Zumla A: Real-time RT-PCR normalization; strategies and considerations. Genes Immun 2005, 6(4):279-284.

29. Basso K, Sumazin P, Morozov P, Schneider C, Maute RL, Kitagawa Y, Mandelbaum J, Haddad J Jr, Chen CZ, Califano A, Dalla-Favera R: Identification of the Human Mature B Cell miRNome. Immunity 2009, 30(5):744-752.

30. Rosenfeld N, Aharonov R, Meiri E, Rosenwald S, Spector Y, Zepeniuk M, Benjamin $H$, Shabes N, Tabak S, Levy A, Lebanony D, Goren Y, Silberschein E, Targan N, Ben-Ari A, Gilad S, Sion-Vardy N, Tobar A, Feinmesser M, Kharenko O, Nativ O, Nass D, Perelman M, Yosepovich A, Shalmon B, Polak-Charcon S, Fridman E, Avniel A, Bentwich I, Bentwich Z, Cohen D, Chajut A, Barshack I: MicroRNAs accurately identify cancer tissue origin. Nat Biotechnol 2008, 26(4):462-469.

31. Ferracin $M$, Pedriali $M$, Veronese $A$, Zagatti $B$, Gafà $R$, Magri $E$, Lunardi $M$ Munerato G, Querzoli G, Maestri I, Ulazzi L, Nenci I, Croce CM, Lanza G, Querzoli P, Negrini M: MicroRNA profiling for the identification of cancers with unknown primary tissue-of-origin. J Pathol 2011, 225(1):43-53.

32. Varadhachary GR, Spector $Y$, Abbruzzese JL, Rosenwald S, Wang H, Aharonov R, Carlson HR, Cohen D, Karanth S, Macinskas J, Lenzi R, Chajut A, Edmonston TB, Raber MN: Prospective gene signature study using microRNA to identify the tissue of origin in patients with carcinoma of unknown primary. Clin Cancer Res 2011, 17(12):4063-4070.

33. Liang $Y$, Ridzon $D$, Wong $L$ and Chen $C$ : Characterization of microRNA expression profiles in normal human tissues. BMC Genomics 2007, 8:166.

34. Arribas AJ, Campos-Martín Y, Gómez-Abad C, Algara P, Sánchez-Beato M, Rodriguez-Pinilla MS, Montes-Moreno S, Martinez N, Alves-Ferreira J, Piris MA, Mollejo M: Nodal marginal zone lymphoma: gene expression and miRNA profiling identify diagnostic markers and potential therapeutic targets. Blood 2012, 119(3):e9-e21.

35. Robertus JL, Harms G, Blokzijl T, Booman M, de Jong D, van Imhoff G, Rosati S, Schuuring $E$, Kluin $P$, van den Berg A: Specific expression of miR-17-5p and 
miR-127 in testicular and central nervous system diffuse large B-cell lymphoma. Mod Pathol 2009, 22(4):547-555.

36. Volinia S, Calin GA, Liu CG, Ambs S, Cimmino A, Petrocca F, Visone R, Iorio M, Roldo C, Ferracin M, Prueitt RL, Yanaihara N, Lanza G, Scarpa A, Vecchione A, Negrini M, Harris CC, Croce CM: A microRNA expression signature of human solid tumors defines cancer gene targets. Proc Natl Acad Sci USA 2006, 103(7):2257-2261.

37. Mendell JT: miRiad roles for the miR-17-92 cluster in development and disease. Cell 2008, 133(2):217-222.

38. Nilsson S, Möller C, Jirström K, Lee A, Busch S, Lamb R, Landberg G: Downregulation of miR-92a is associated with aggressive breast cancer features and increased tumour macrophage infiltration. PLoS One 2012, 7(4):e36051.

39. Wienholds E, Plasterk RH: MicroRNA function in animal development. FEBS Lett 2005, 579:5911-5922.

40. Santanam U, Zanesi N, Efanov A, Costinean S, Palamarchuk A, Hagan JP Volinia S, Alder H, Rassenti L, Kipps T, Croce CM, Pekarsky Y: Chronic lymphocytic leukemia modeled in mouse by targeted miR-29 expression. Proc Natl Acad Sci USA 2010, 107:12210-12215.

41. Bandyopadhyay S, Friedman RC, Marquez RT, Keck K, Kong B, Icardi MS, Brown KE, Burge CB, Schmidt WN, Wang Y, McCaffrey AP: Hepatitis C virus infection and hepatic stellate cell activation down-regulate miR-29: miR29 overexpression reduces hepatitis C viral abundance in culture. J Infect Dis 2011, 203(12):1753-1762.

42. Fazi F, Rosa A, Fatica A, Gelmetti V, De Marchis ML, Nervi C, Bozzoni I: A minicircuitry comprised of microRNA-223 and transcription factors NFI-A and C/EBPalpha regulates human granulopoiesis. Cell 2005, 123:819-831.

43. Fukao T, Fukuda Y, Kiga K, Sharif J, Hino K, Enomoto Y, Kawamura A, Nakamura K, Takeuchi T, Tanabe M: An evolutionarily conserved mechanism for microRNA-223 expression revealed by microRNA gene profiling. Cell 2007, 129:617-631.

44. Eyholzer M, Schmid S, Schardt JA, Haefliger S, Mueller BU, Pabst T: Complexity of miR-223 regulation by CEBPA in human AML. Leuk Res 2009, 34(5):672-676

45. Eyholzer M, Schmid S, Wilkens L, Mueller BU, Pabst T: The tumoursuppressive miR-29a/b1 cluster is regulated by CEBPA and blocked in human AML. Br J Cancer 2010, 103(2):275-284.

doi:10.1186/1471-2334-14-S5-S6

Cite this article as: Bruni et al:: microRNA levels in paraffin-embedded indolent B-cell non-Hodgkin lymphoma tissues from patients chronically infected with hepatitis B or C virus. BMC Infectious Diseases 2014 14(Suppl 5): S6.

\section{Submit your next manuscript to BioMed Central and take full advantage of:}

- Convenient online submission

- Thorough peer review

- No space constraints or color figure charges

- Immediate publication on acceptance

- Inclusion in PubMed, CAS, Scopus and Google Scholar

- Research which is freely available for redistribution 